\title{
Effects of Simulation-Guided Microwave Presintering Process on the Preparation and Final Properties of Pure Ceramic Rings: Lower Sintering Temperature and Higher Mechanical Properties
}

\author{
Xiao Lu, ${ }^{1}$ Tong-Tong Zhou, ${ }^{1}$ Feng-He Zhao, ${ }^{2}$ Xiao-Xiong Wang, ${ }^{1}$ Li-Xiang Chen (D), \\ and Yun-Ze Long $\mathbb{D}^{1}$ \\ ${ }^{1}$ Department of Physics, Qingdao University, Qingdao 266071, China \\ ${ }^{2}$ Qingdao SME Public Service Center, Qingdao 266034, China \\ Correspondence should be addressed to Li-Xiang Chen; clxwlx@163.com and Yun-Ze Long; yunze.long@163.com
}

Received 8 May 2020; Revised 12 July 2020; Accepted 8 August 2020; Published 7 September 2020

Academic Editor: Antonio Caggiano

Copyright (C) 2020 Xiao Lu et al. This is an open access article distributed under the Creative Commons Attribution License, which permits unrestricted use, distribution, and reproduction in any medium, provided the original work is properly cited.

\begin{abstract}
In order to improve the performance and endurance of steel rings used for twisting and winding yarns in the textile industry, a more wear-resistant ceramic version is studied and examined by conducting multiple simulations combined with microwave sintering experiments of the ring preparation process, aiming to reduce manufacturing costs and improve efficiency. The threedimensional (3D) electromagnetic field simulation software HFSS is used to simulate the electromagnetic field distribution in the microwave sintering cavity and to determine the electromagnetic region with the most uniform electromagnetic field to guide the microwave sintering experiments. The $3 \mathrm{Y}$-TZP ceramic rings are shaped by gel-casting. The effect of presintering on the performance of ceramic rings is investigated by applying conventional sintering and microwave sintering methods. The experimental results show that the simulation-guided microwave sintering process can resolve the deficiency of uneven microwave sintering at low temperatures. Comparing the final sintering temperatures and mechanical properties of the final ceramic-sintered rings obtained by microwave presintering to those obtained by conventional presintering, microwave presintered sample has a final temperature of $1400^{\circ} \mathrm{C}$, which is $100^{\circ} \mathrm{C}$ lower than that of conventional presintering, which is $1500^{\circ} \mathrm{C}$; its average grain size of $0.18 \mu \mathrm{m}$ is dramatically smaller than that of conventional presintering, which is $0.24 \mu \mathrm{m}$, with about $80 \%$ of the grain sizes present in the range of $0.1-0.2 \mu \mathrm{m}$ and a relative density of about $99 \%$, as opposed to conventional presintering's $70 \%$ falling between 0.2 and $0.3 \mu \mathrm{m}$ and relative density of about $98 \%$; the Vickers hardness and fracture toughness for microwave presintered sample reach $1550 \mathrm{~kg} \cdot \mathrm{f} \cdot \mathrm{mm}^{-2}$ and $9.05 \mathrm{MPa} \mathrm{m}^{1 / 2}$, respectively, which are both greater than $1431 \mathrm{~kg} \cdot \mathrm{f} \cdot \mathrm{mm}^{-2}$ and $8.86 \mathrm{MPa} \mathrm{m}^{1 / 2}$ in the conventional samples.
\end{abstract}

\section{Introduction}

Steel rings are one of the essential components in the yarn twisting and winding process in spinning production and are consumed in large quantities every year. Traditional steel rings are not high-temperature-resistant, easily wear and tear, and have a short service life, which cannot meet the industrial patterns of the latest generation [1]. Ceramics are known to have outstanding advantages in terms of antiabrasion and providing more reliable high-temperatureresistance, so researchers have tried to improve the steel ring wear-resistance by delivering ceramic-coating and other related methods [2]; yet, the process of producing such rings is complicated and costly and hence cannot reach a proper cost-effective ratio. The 3Y-TZP ceramic material has the mechanical properties of high stability, high strength and toughness, and resistance to high temperature, corrosion, and abrasion [3-5]. The practice of replacing ceramic-coated steel rings with pure ceramic rings throughout the process of ring-spinning, where high-speed grinding continuously occurs, is a solid technique and an innovative breakthrough. The major limitation that restrains the pure ceramic rings from a large-scale application in the market is the high costs during their preparation process. If the preparation costs for 
the ceramic rings can be reduced, especially in the sintering process, the other steel rings will be superseded in an extensive range of yarn spinning industry.

Currently, conventional sintering is restricted by its natural impediments of uneven temperature and long heating time, whereas microwave sintering features a fast heating speed and more uniform heating and delivers consistent temperature fields [6-8]. Microwave sintering technology is broadly adopted in the preparation of other materials: $\mathrm{BCTZ}$ piezoelectric ceramics [9], $\mathrm{BaTiO}_{3}$ ceramics [10], lithium-ion battery electrodes $\left(\mathrm{Li}_{2} \mathrm{TiO}_{3}\right.$ ceramics) [11], $\mathrm{ZnO}$-based piezoresistive materials [12], $\mathrm{Si}_{3} \mathrm{~N}_{4}$ ceramics [13], Ni-TiC composites [14], Cu-MWCNT nanocomposites [15], graphite alkene-ceramic composites [16], $\mathrm{BaTiO}_{3}-\mathrm{Ag}$ high-energy capacitors [17], various composite materials and hardened alloy materials $[18,19]$, high-performance heat-resistant molybdenum materials [20], and titanium alloy materials [21]. Nevertheless, while utilizing microwave sintering, there are circumstances where the sample fails to absorb microwaves uniformly at low temperatures, leading to the results of uneven heating and potential cracks on the final products. The most effective solution addressing this problem is to evenly distribute the microwave power on the sample during sintering, which emphasizes the uniformity of the microwave electromagnetic field on the sample in the sintering cavity. Since the temperature-dependent variation of the dielectric properties for some sample materials can influence their microwave-absorption energy and their electromagnetic field distribution, follow-ups beyond this study on the electromagnetic field distribution need to consider and modify such impact with research on temperature field simulation. To achieve this goal, this study applies the three-dimensional electromagnetic simulation technology to simulate the microwave electromagnetic fields and ascertain the most evenly distributed areas within the sintering cavity to guide the specific microwave sintering process for the most time-labor-efficient method. Therefore, performing an electromagnetic simulation to locate the most effective sintering region is a critical procedure to avoid defects in the final products.

Casting the $3 \mathrm{Y}$-TZP ceramic ring using ultrafine $3 \mathrm{Y}$ TZP zirconia powder with consistent microstructure as the raw material, as an accurate powder selection, and as a well-organized gel-casting process will guarantee the requirements of ceramic rings, including shape size, particularly density consistency, to be satisfied and serves as the prerequisite to a successful upcoming microwave sintering. The key to meeting the performance criteria of the ceramic rings is to have the sintered samples composed with constant micron-size particles, and presintering is a nonnegligible step to ensure that this happens. Given that the cracking and deforming of the final product can be prevented by eliminating the 3\% organic remains, which degrade the overall product qualities by generating excessive pores during evaporation on the ring samples, within the ceramic-ring samples, an effective presintering operation is expected before the final sintering process begins. Studies have shown that the temperature at which most organic substances can be eliminated is around $510^{\circ} \mathrm{C}$ [22]. In order to prevent the residual of organic substances, the presintering temperature of samples in this study is set to $600^{\circ} \mathrm{C}$. Theoretically, microwave presintering is more likely to produce better-structured high-property ceramic rings compared to conventional presintering, but it is correct only when the ceramic ring samples are placed in the proper electromagnetic fields to avoid the problem of inconstant microwave absorption during the presintering procedure. To find such proper electromagnetic fields, performing a microwave presintering simulation is an outstanding method used in the real presintering scenario.

This study focuses on exploring the influences of the microwave presintering process on the final ceramic ring samples with electromagnetic field simulation. Modeling is based on the microwave sintering equipment in the fine ceramic lab; High Frequency Structure Simulator (HFSS) simulates the electromagnetic field distribution in the microwave sintering cavity to obtain the region with the most homogeneous distribution of electromagnetic fields; the result of this simulation is used as a guide to the microwave presintering and the entire sintering process for $3 \mathrm{Y}$-TZP ceramic rings. Two groups of casted ceramic ring samples are set up: one is prepared for simulation-guided microwave presintering, and the other is for conventional presintering. After the pre-sintering processes are completed, both groups are moved to the identical microwave sintering environments and are sintered with the same method following equivalent heating curves; the stated experimental procedure is then repeated for over a hundred times. The compositions of both samples are assessed by Energy Dispersive Spectroscopy (EDS), and their microstructures are examined by Scanning Electron Microscopy (SEM) to determine an optimal presintering method and the final sintering temperature with analysis on relative densities, Vickers hardness, and fracture toughness at different sintering temperatures.

\section{Experimental Procedure}

In this study, acrylamide (AM), $\mathrm{N}, \mathrm{N}^{\prime}$-methylenebisacrylamide (MBAm), and ammonium polymethacrylate (PMAA-NH4), as an organic monomer, a cross-linking agent, and a dispersant, respectively, were mixed according to the ratio shown in Table 1 to obtain a premix.

The 3Y-TZP powder with the size of $100 \mathrm{~nm}$ was poured into the premix, stirred, and ball-milled to mix thoroughly, and ammonia solution was used to adjust the $\mathrm{pH}$ of the premix to 9. Ammonium persulfate (APS) as the initiator and the Tetramethylethylenediamine (TEMED) as the catalyst proportionally were added to the slurry and immediately cast into the ring mold to form a ring-shaped gel. One sample was cast into a round-shape model with a diameter of $15 \mathrm{~mm}$ and thickness of $3 \mathrm{~mm}$, and another one was cast into a $40 \times 5 \times 6 \mathrm{~mm}^{3}$ rectangular-shape model for the later measurement on Vickers hardness and fracture toughness, respectively. After heating the mold to about $70^{\circ} \mathrm{C}$, the gel was transformed into a body with a fixed shape and then 
TABLE 1: The ratio of reagents.

\begin{tabular}{|c|c|c|c|c|c|}
\hline \multirow{2}{*}{$\begin{array}{l}\text { Ceramic powder } \\
\text { 3Y-TZP }\end{array}$} & \multicolumn{5}{|c|}{ Other reagents } \\
\hline & $\mathrm{AM}$ & MBAm & TEMED & APS & $\mathrm{PMAA}_{-} \mathrm{NH}_{4}$ \\
\hline 100 (wt\%) & $2.5(\mathrm{wt} \%)$ & $0.01(w t \%)$ & 0.05 (wt\%) & $0.1(\mathrm{wt} \%)$ & $1.5(\mathrm{wt} \%)$ \\
\hline
\end{tabular}

solidified and demolded to form ceramic blanks. The inner diameter of the upper bottom surface of the blanks was $45 \mathrm{~mm}$, and the outer diameter was $55 \mathrm{~mm}$; the inner diameter of the lower bottom surface was the same as the upper inner bottom surface, and the outer diameter was $6 \mathrm{~cm}$; the overall thickness was $30 \mathrm{~mm}$.

Samples were divided into two groups with twelve samples for each, with only one sample sintered in a single experiment; the experiment was repeated twelve times. Group A samples were presintered in a muffle furnace with a heating curve as shown in Figure 1. Group B samples were microwave-presintered following the guide of the electromagnetic field simulation experiment result with a heating curve as shown in Figure 1. Since the heating process in microwave sintering is holistic, a positive temperature gradient throughout both the inside and the outside of the sample is more efficient for the removal of the organic remains. In this way, defects in the samples can be largely avoided, and the quality of the final sintering process can be ensured.

The two presintered samples were naturally cooled to room temperature, and the final microwave sintering started for both at $1300^{\circ} \mathrm{C}, 1350^{\circ} \mathrm{C}, 1400^{\circ} \mathrm{C}, 1450^{\circ} \mathrm{C}$, and $1500^{\circ} \mathrm{C}$. Each sintering temperature corresponds to the heating rate shown in Figure 2. At this point in the sintering process, the sintering auxiliary material $\mathrm{SiC}$ could be properly added to the insulation material within the sintering cavity to ensure a higher and more uniform heating of the ceramic ring samples. Microwave sintering equipment was the V3000 microwave sintering furnace (Changsha Longtai Microwave Thermal Co., Ltd.), with the microwave source operating frequency being $2.45 \mathrm{GHz}$ and adjustable power from 0 to $3 \mathrm{~kW}$ continuously. Temperatures of the samples within the sintering cavity were measured with an infrared thermometer.

The electromagnetic field distribution in the microwave sintering cavity was simulated using the $3 \mathrm{D}$ electromagnetic field simulation software HFSS. The study uses a laboratory microwave sintering furnace V3000 from Changsha Longtai Microwave Thermal Co., Ltd., as the model, with the dimensions of rectangular waveguides being $92 \times 45 \times 380 \mathrm{~mm}^{3}$. The diameter of the cylindrical resonant cavity is $D=500 \mathrm{~mm}$, the height is $h=400 \mathrm{~mm}$, and the thickness of the resonant cavity is $20 \mathrm{~mm}$. There is a horn between the rectangular waveguide and the resonant cavity, with the small crosssectional size of the horn being $150 \times 100 \mathrm{~mm}$ and the large cross-sectional size being $200 \times 150 \mathrm{~mm}$. As illustrated, the insulation consists of two layers: the outer layer made of mullite fiber has a radius of $80 \mathrm{~mm}$, a height of $220 \mathrm{~mm}$, and a thickness of $30 \mathrm{~mm}$, while the inner layer made of alumina hollow spheres has an inner radius of $60 \mathrm{~mm}$, a height of $180 \mathrm{~mm}$, and a thickness of $5 \mathrm{~mm}$.

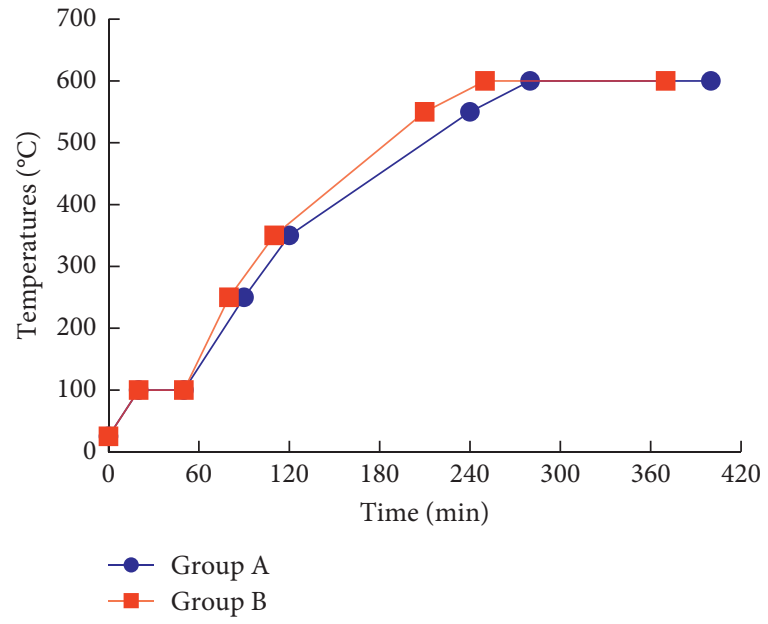

Figure 1: Presintering heating curve of samples of group A and group $\mathrm{B}$.

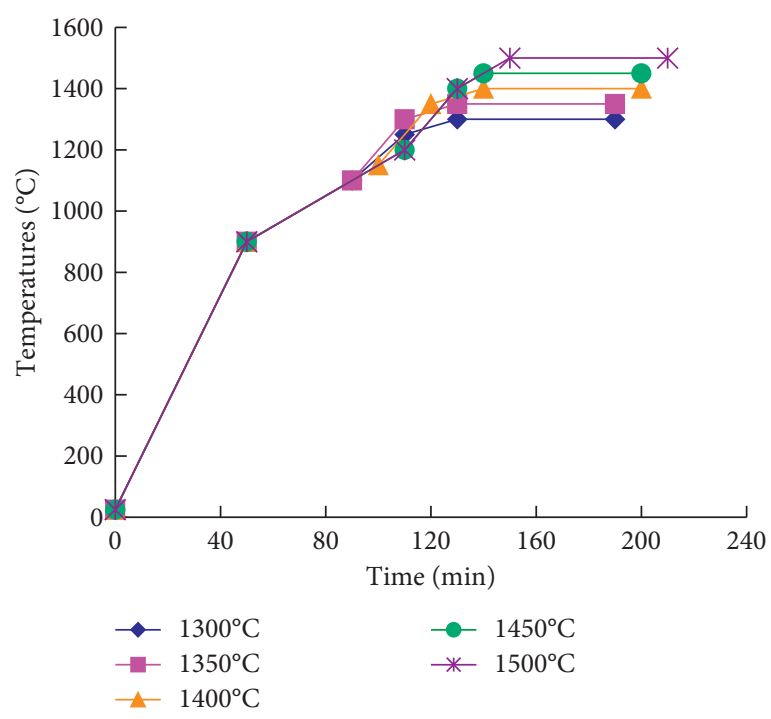

FIGURE 2: Sample heating rate at different sintering temperatures.

Both insulation layers are placed on a disk-shaped stainless-steel-made platform with a radius of $180 \mathrm{~mm}$, at about $80 \mathrm{~mm}$ from the bottom of the cavity. Then, simulation and analysis of the electromagnetic field at different sample placement locations are carried out by HFSS software to find the optimal height to place the sintered samples in the sintering cavity.

The composition of the samples was analyzed using an Orbis microbeam X-ray fluorescence spectrometer from EDAX Inc., and an FEI Nova NanoSEM400 field emission scanning electron microscope (SEM) was designed to observe the internal structure; the particle size distribution was calculated using the Nano Measurer 1.2 software, and the 
density of the sample was measured by the drainage method using a ZMD-2 electron densitometer by Shanghai Fangrui Instrument Co., Ltd. The round-shaped and rectangularshaped samples prepared under the exact same experimental conditions to the ceramic ring samples were used to measure the Vickers hardness and the fracture toughness of the samples. Samples were cut and polished, using an HXD1000 digital microhardness tester from Shanghai Taiming Optical Instrument Co., Ltd., to select the three positions to measure the Vickers hardness with a load of $1000 \mathrm{gf}$, and then the average hardness was obtained. The CTM2200S microcomputer servo-controlled electronic universal materials tester was used to measure fracture toughness of the samples with a single-sided notched beam method.

\section{Electromagnetic Simulation}

3.1. Establish Sintering Cavity and Sample Model. The reallife dimensions of our laboratory microwave sintering oven V3000 are used to construct the model. The outer shell of the sintering cavity and the disk below the insulation layer are made of stainless steel, and the rectangular waveguide is made of brass. The materials for the inner and outer layers of insulation are set to be mullite fibers and aluminum oxide hollow spheres, respectively. In our experiments, the selfadaptive method is adopted to delineate grids, and the boundaries are configured to the ideal conductor boundary conditions. The port is set as a rectangular waveguide port and its material characteristics and cross sections are consistent with the rectangular waveguide. The excitation mode is the wave port excitation with $2.45 \mathrm{GHz}$ before and after adding the scan frequency.

Figure 3 is a schematic diagram of loading the samples and setting the axes. The samples are placed in the center of the disk in the sintering cavity, and the origin of the axis is arranged to be the center of the disc's upper surface for observation purposes.

3.2. Electric Field Distribution Simulation in Samples. The electromagnetic field distributions of the loaded 3Y-TZP samples at different sintering positions are simulated by parametric scanning. All selected samples are placed horizontally, and the changes in the electromagnetic field distribution with the samples moving along the plane are observed and recorded. Using the coordinate axis shown in Figure 3 as a reference, the $x$-coordinate and $y$-coordinate values for the center point $\mathrm{O}$ of the ring are modified at the bottom of the ceramic ring, while the $z$-coordinate is fixed as 0 .

The level of uniformity is measured with two values: the field uniformity ratio and the intensity-area ratio. For the electric field at a sample cross section, the field uniformity ratio refers to the ratio of the area of the region with the greatest uniformity to the area of the entire cross section in the distribution map. The intensity-area ratio is the ratio of the region with the greatest difference in field strength from the region of greatest uniformity to the area of the entire cross section. According to the line plot shown in Figure 4, the vertical

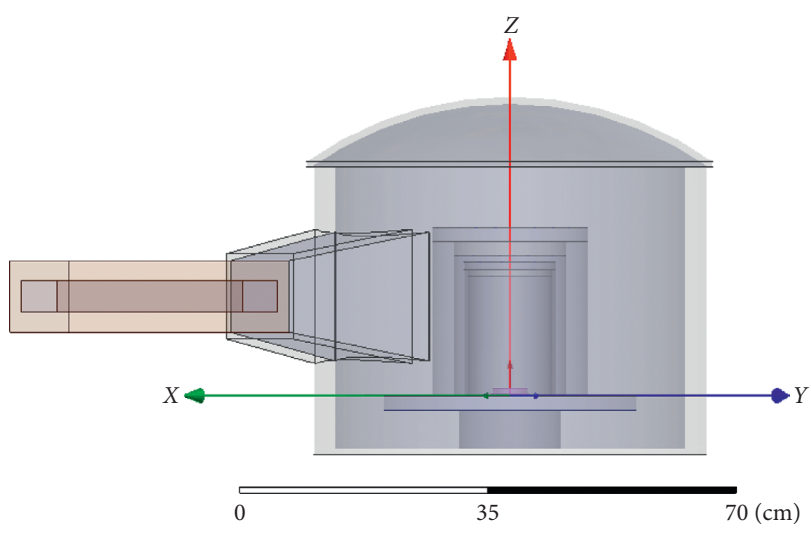

FIGURE 3: Schematic diagram of loading sample and setting up coordinate axes.

coordinates of Figures 4(a) and 4(b) represent the field uniformity ratio and the intensity-area ratio of the sample, correspondingly. The horizontal coordinates represent the $y$ coordinate values of point $\mathrm{O}$ at the bottom center of the steel ring, and the different colored polylines represent the different $x$-coordinate values of point $\mathrm{O}$. From Figure 4 , it is clear that the overall field uniformity reaches its maximum when the sample center is located at the coordinates $(2,2)$; at the same time, the intensity-area ratio is at its minimum, indicating the most uniform distribution of the electromagnetic field within the sample.

Next, the electromagnetic field distributions of the samples placed at different heights are studied. Taking the bottom of the insulation layer as the reference plane and fixing point $\mathrm{O}$ as $(x=2, y=2)$, the coordinate position in the $Z$ direction is scanned to determine the ideal position for sintering. As shown in Figure 5, the field uniformity gradually decreases as the coordinates of the center are shifted from $0 \mathrm{~cm}$ to $3 \mathrm{~cm}$ along the $z$-axis. An increase in the intensity-area ratio suggests a diminishing uniformity of field distribution. Considering the dashed-line changes in field uniformity and intensity-area ratio, it is noticed that as the sample continues to move until the sample is at $z=9 \mathrm{~cm}$, with the field uniformity increased to nearly $60 \%$ and the intensity-area ratio reaching a minimum value of $15 \%$, the best field distribution uniformity is located. However, after $9 \mathrm{~cm}$, the field uniformity reveals a decreasing trend, and the intensity gradient increases. If the height of the material is too high or too low, it will not be able to absorb microwaves steadily, and therefore the overall sintering state of the sample is at its best when the sample center is near $9 \mathrm{~cm}$.

To further investigate the effect of height variation on field distribution, the range of height variation is reduced. The height of the samples is adjusted to vary between 8.3 and $10.1 \mathrm{~cm}$, and the various steps are $0.3 \mathrm{~cm}$ each time. The obtained internal electric field distributions of samples from different dimensions are recorded in Figure 6, from which we can see that as the sample moves from $8.3 \mathrm{~cm}$ to $8.9 \mathrm{~cm}$ in the $z$-axis, the hot spots slowly disappear, and the electric field uniformity is gradually increasing. When the sample moves upward again, the nonuniformity reappears in the sample and gradually aggregates through the dispersed form, eventually 


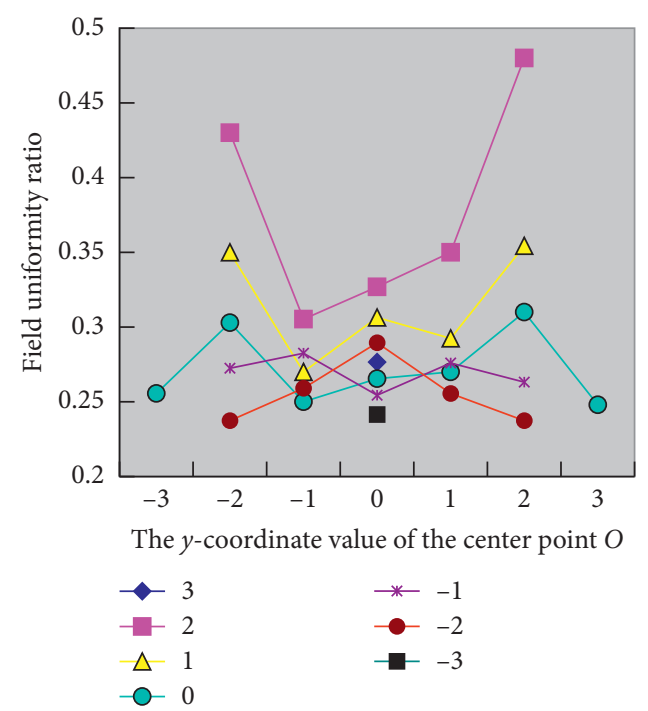

(a)

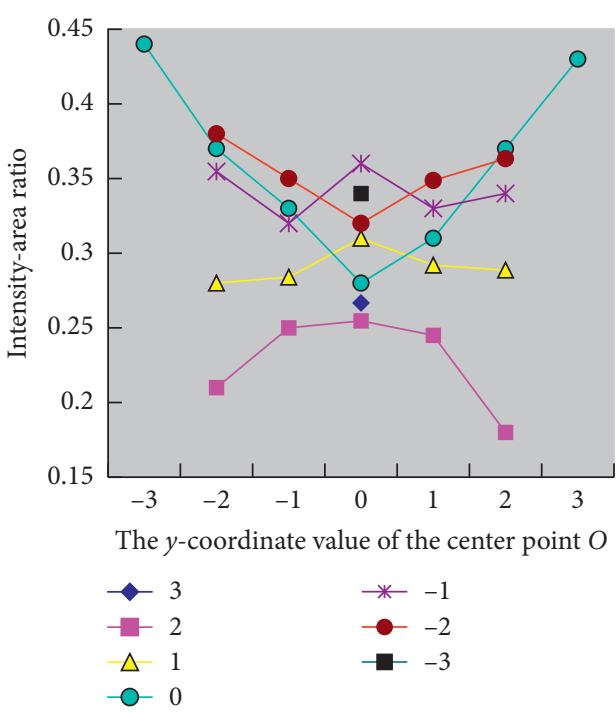

(b)

Figure 4: Variation of field uniformity (a) and intensity-area ratio (b) of samples at different positions $(x, y)$ on the plane.

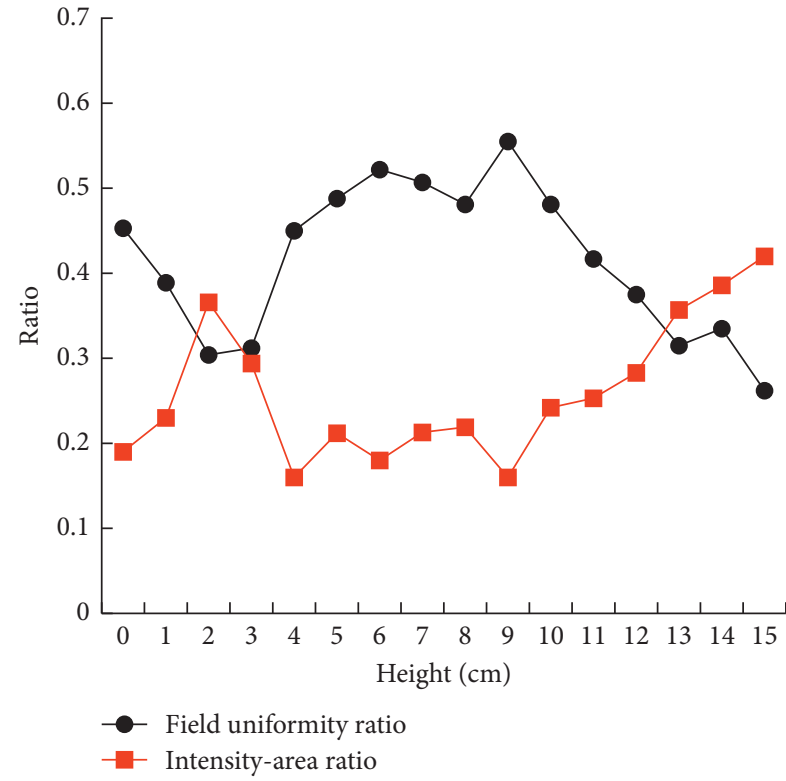

FIGURE 5: The variation of field uniformity and intensity-area ratio at different heights.

forming new hot spots. As the height is increased to $10.1 \mathrm{~cm}$, the number of hot spots rises from one to two, and the uniformity decreases again. As a result, the electromagnetic field is now unstable and the quality of the sintered samples at this height will not be very good in practice.

To summarize, the ceramic ring blanks in group B should be presintered by microwave at the coordinates $(2,2,8.9)$, which is indicated on the axis shown in Figure 3, with a sintering temperature of $600^{\circ} \mathrm{C}$. The same location should be chosen for the final microwave sintering process of the samples of both group A and group B.

\section{Experimental Results and Discussion}

From the pictures in Figures 7-10, samples in group A and group B have different grain sizes and uniformities at different microwave sintering temperatures. Observing the two-particle size distributions in Figures 8 and 10, as the sintering temperature increases, the peak of the curve increases and is distorted to move left and become narrower. This implies that as the sintering temperature increases, the grain size becomes smaller and smaller, the number of grains distributed in the same area increases, and the distribution becomes more and more uniform. In Figures 7 and 8 , the best microscopic appearance of the conventional presintered group A samples is achieved at $1500^{\circ} \mathrm{C}$, where about $70 \%$ of the grains are distributed between 0.2 and $0.3 \mu \mathrm{m}$. In Figures 9 and 10, the microwave-presintered samples in group $\mathrm{B}$ have the smallest grain size and pore at $1400^{\circ} \mathrm{C}$. At this time, about $80 \%$ of the grains are distributed between 0.1 and $0.2 \mu \mathrm{m}$. In Figure 9(d), when the temperature rises to $1450^{\circ} \mathrm{C}$, the sample quality is inferior. Therefore, in combination with the two pictures in Figures 7(d) and 9(c), we conclude that the sample treated by microwave presintering has smaller porosity and the grain size distribution is small and uniform.

From Figure 11, it can be seen that the average grain size of the two groups $\mathrm{A}$ and $\mathrm{B}$ gradually decreases with the increase of the sintering temperature. At $1500^{\circ} \mathrm{C}$, the average grain size of samples in group $\mathrm{A}$ is at its smallest value: $0.240 \mu \mathrm{m}$. At $1400^{\circ} \mathrm{C}$, the average grain size of samples in group B is at its smallest value: $0.180 \mu \mathrm{m}$. Therefore, small grain size can be obtained at lower sintering temperatures for samples that have been treated by the microwave presintering process, due to the fact that, in the cementation stage, the removal of organic remains is done from the inside out, whereas, in the conventional sintering method, there is an induction process that produces defects during evaporation. This problem can be overcome by the microwave 


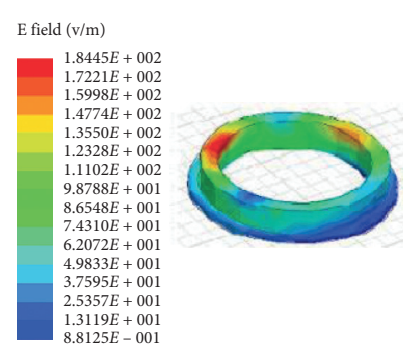

(a)

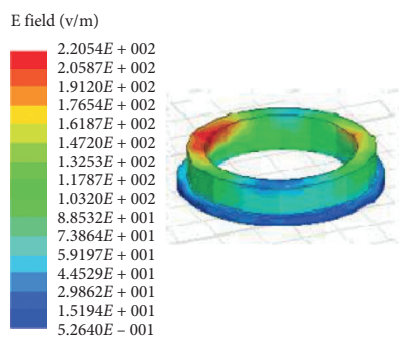

(b)

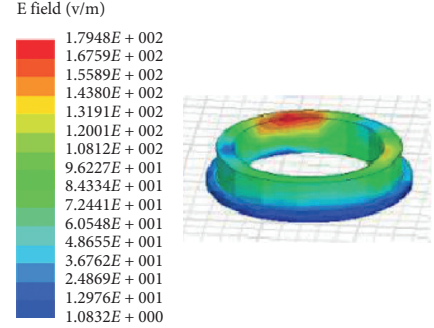

(e)
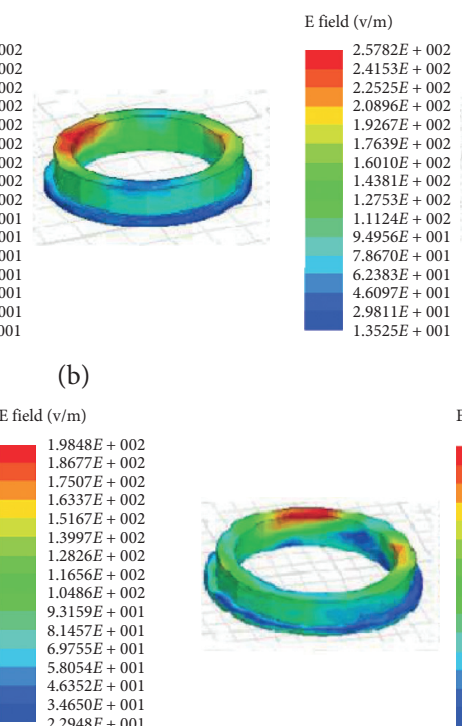

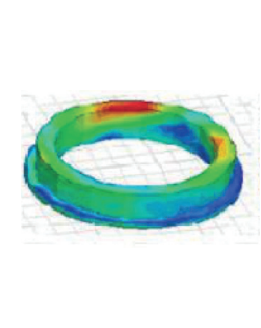

(f)

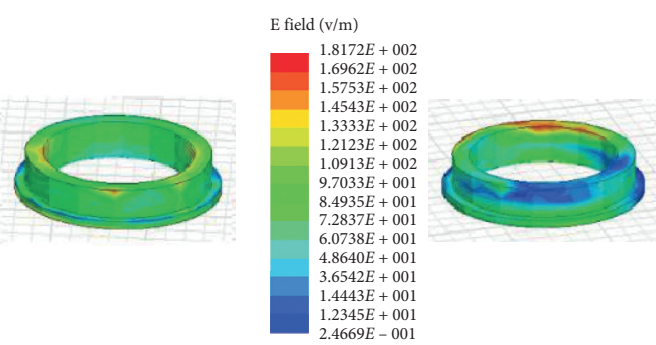

(c)

(d)
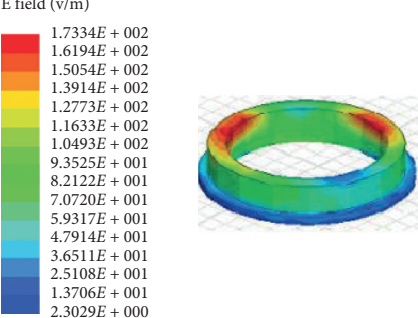

(g)

FIGURE 6: Electric field distribution in ceramic steel ring at different heights $(z$-coordinate values). (a) $8.3 \mathrm{~cm}$. (b) $8.6 \mathrm{~cm}$. (c) $8.9 \mathrm{~cm}$. (d) $9.2 \mathrm{~cm}$. (e) $9.5 \mathrm{~cm}$. (f) $9.8 \mathrm{~cm}$. (g) $10.1 \mathrm{~cm}$.
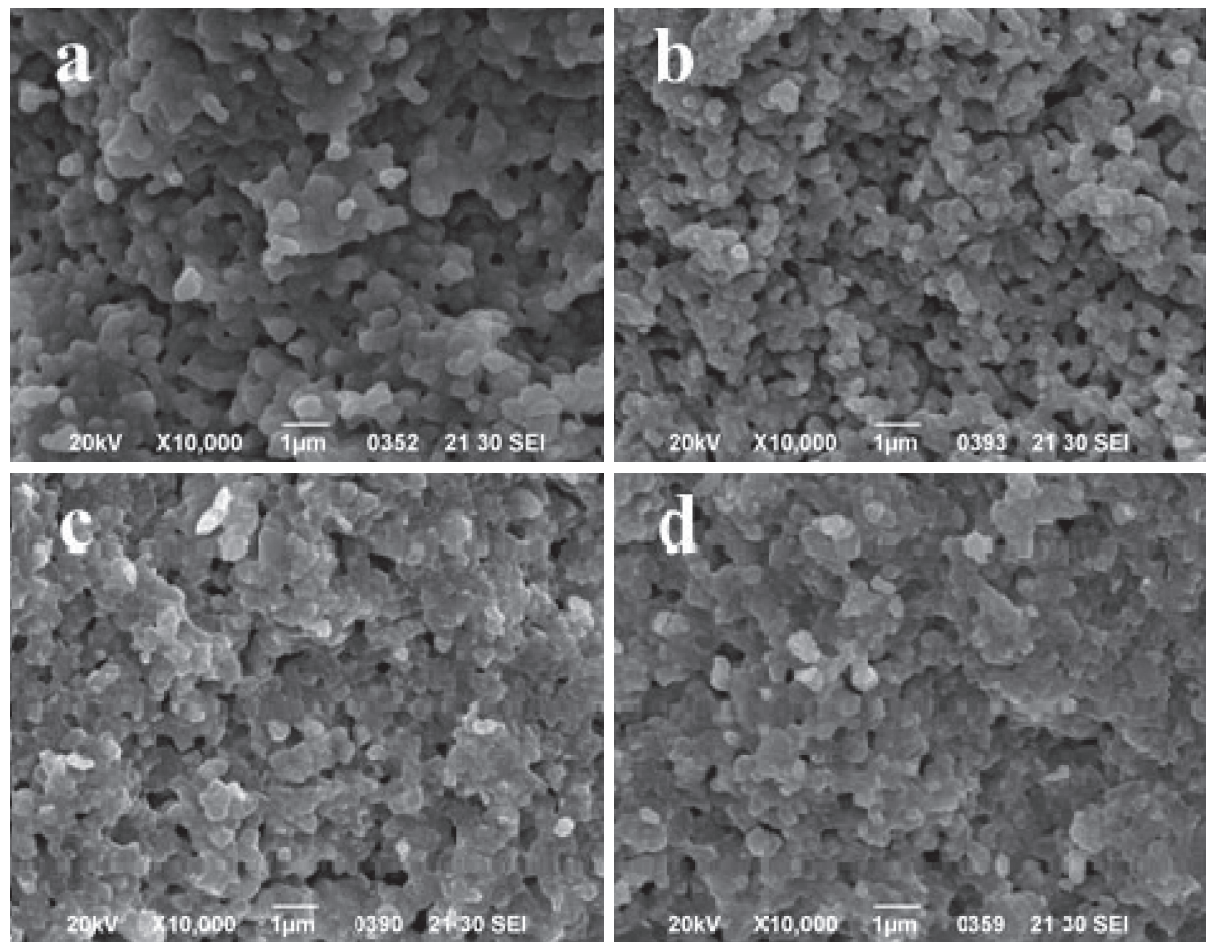

Figure 7: SEM images of four ceramic rings of group A obtained at different microwave sintering temperatures. (a) $1350^{\circ} \mathrm{C}$, (b) $1400^{\circ} \mathrm{C},(\mathrm{c}) 1450^{\circ} \mathrm{C}$, and (d) $1500^{\circ} \mathrm{C}$.

presintering process because the microwave sintering process allows the internal structure of the samples to absorb microwave energy uniformly, which generates a positive temperature gradient that is more effective for eliminating organic remains $[23,24]$. Guided by the simulation results, the most uniform electromagnetic field distribution and the most ideal microwave absorption location are found. Taking advantage of microwave features, which are rapid heating, overall heating, uniform temperature field, low thermal stress, and high-energy efficiency, the goal of final sintered samples having smaller grain size and a more uniform distribution is achieved.

Figure 12 shows the composition analysis of the microwave-sintered samples by EDX. The main components 


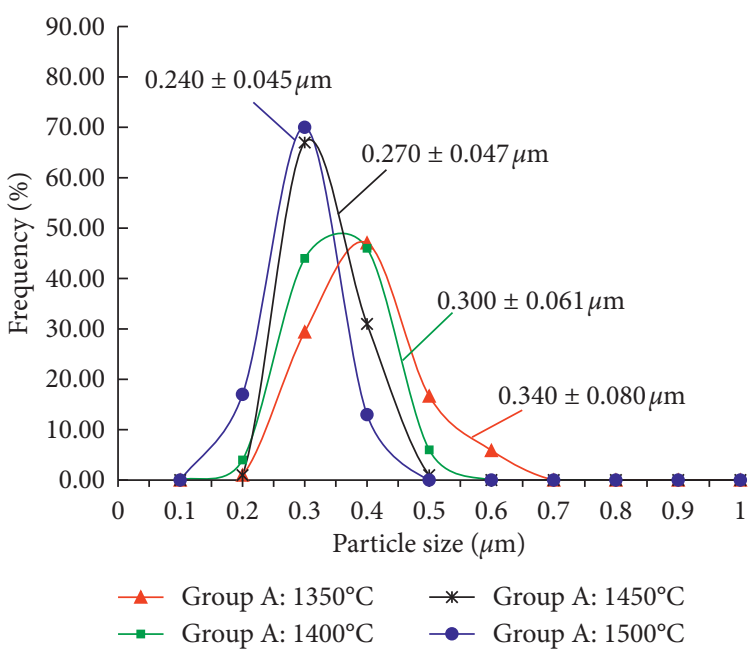

FiguRE 8: Statistics of particle size distribution of four ceramic rings of group A obtained at different microwave sintering temperatures.

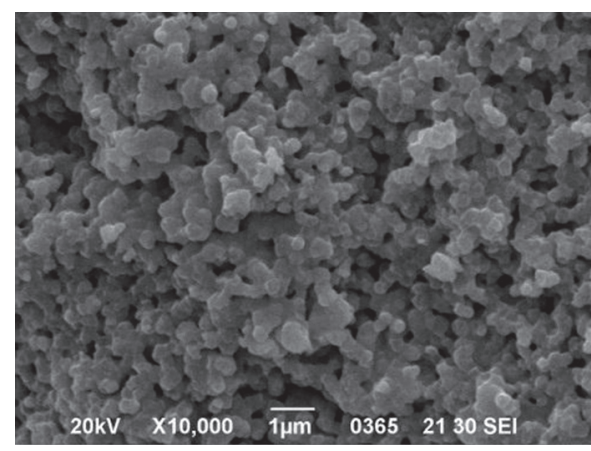

(a)

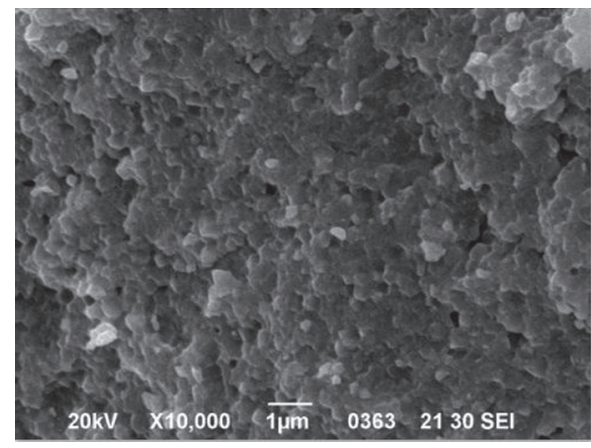

(c)

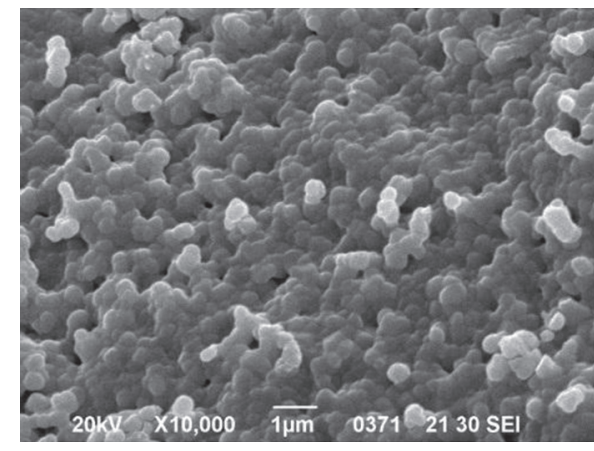

(b)

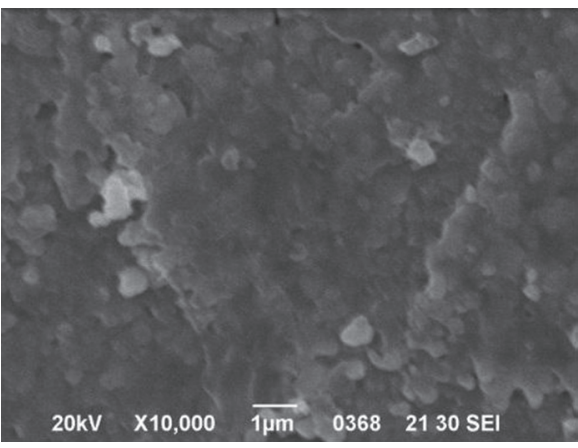

(d)

Figure 9: SEM images of four ceramic rings of group B obtained at different microwave sintering temperatures. (a) $1300^{\circ} \mathrm{C}$, (b) $1350^{\circ} \mathrm{C},(\mathrm{c}) 1400^{\circ} \mathrm{C}$, and (d) $1450^{\circ} \mathrm{C}$.

are $\mathrm{ZrO}_{2}$ with a mass fraction of $92.89 \mathrm{wt} \%$ and the stabilizer $\mathrm{Y}_{2} \mathrm{O}_{3}$ with a mass fraction of $5.51 \mathrm{wt} \%$ (atomic or molar ratio of $3.12 \%$ ), and the remaining component is $\mathrm{Hf}_{2} \mathrm{O}_{3}$ (1.61 wt $\%$ by weight ratio), which has very similar properties to $\mathrm{ZrO}_{2}$.

From the data in Figures 13-15, for samples in group A, it is noticed that the density, Vickers hardness, and the fracture toughness are increasing continuously as the temperature is increased from $1300^{\circ} \mathrm{C}$ to $1500^{\circ} \mathrm{C}$. The relative density at $1500^{\circ} \mathrm{C}$ is $98.20 \%$, the Vickers hardness is $1431 \mathrm{~kg} \cdot \mathrm{f} \cdot \mathrm{mm}^{-2}$, and the fracture toughness is $8.86 \mathrm{MPa} \mathrm{m}^{1 / 2}$.
It can be determined that the final sintering temperature of the samples in group $\mathrm{A}$ is at least $1500^{\circ} \mathrm{C}$. For the samples in group $\mathrm{B}$, after presintering by microwaves, the properties increase, while the temperature is changed from $1300^{\circ} \mathrm{C}$ to $1400^{\circ} \mathrm{C}$, and there is no significant change in the properties of the samples after $1400^{\circ} \mathrm{C}$. Therefore, it can be concluded that the optimal sintering temperature for the samples in group $\mathrm{B}$ is $1400^{\circ} \mathrm{C}$. In this case, the relative density of the samples is $99.67 \%$, which is much higher than that of the samples in group A. Besides, the Vickers hardness is $1550 \mathrm{~kg} \cdot f \cdot \mathrm{mm}^{-2}$, and the fracture toughness is $9.05 \mathrm{MPa} \mathrm{m}^{1 /}$ 


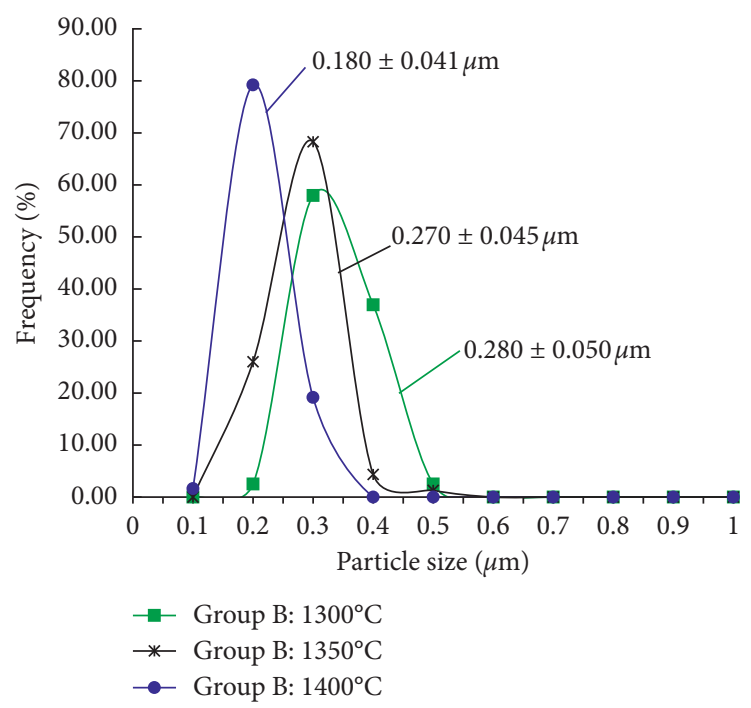

FIGURE 10: Statistics of particle size distribution of three ceramic rings of group B obtained at different microwave sintering temperatures.

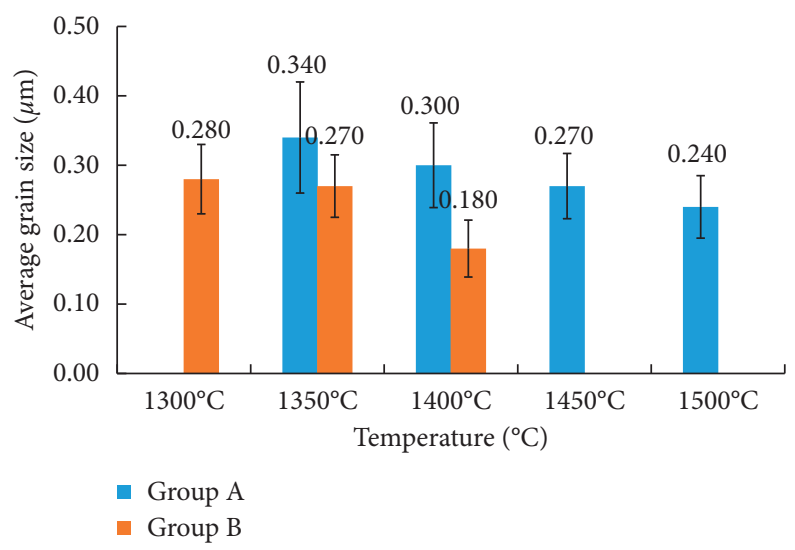

Figure 11: Average grain size of two samples in groups A and B at different sintering temperatures.

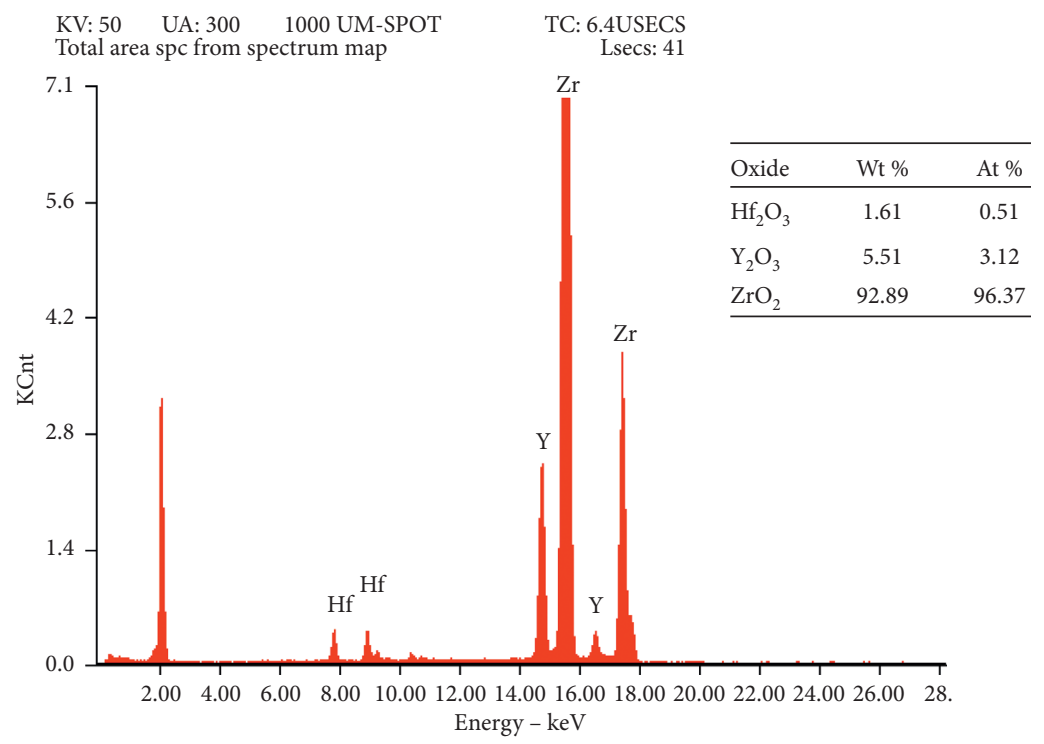

FIgURE 12: Component analysis of the microwave-sintered sample by EDX. 


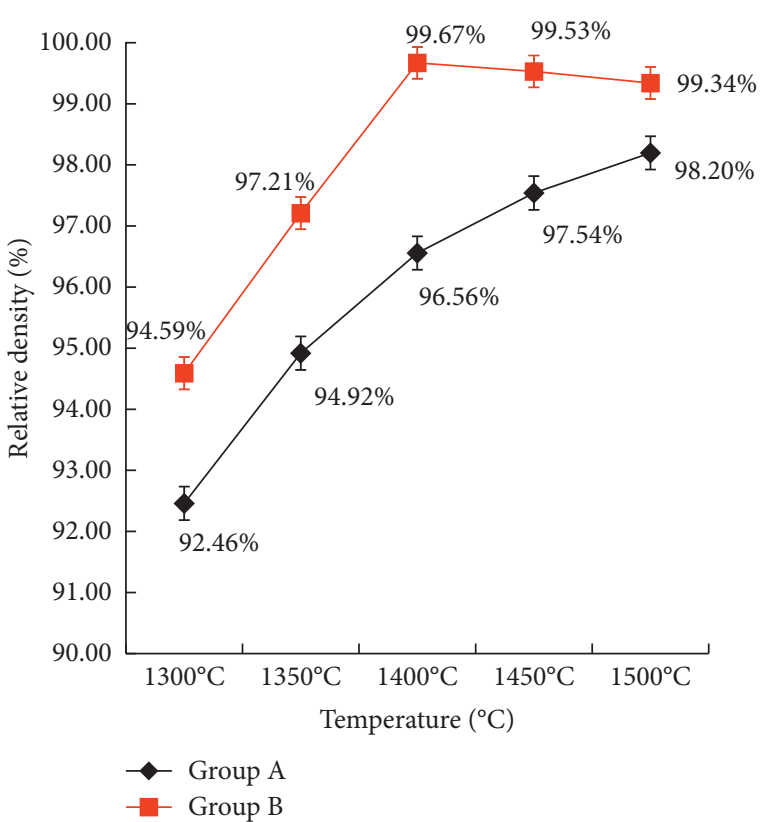

FIGURE 13: Relative density of samples at different microwave sintering temperatures.

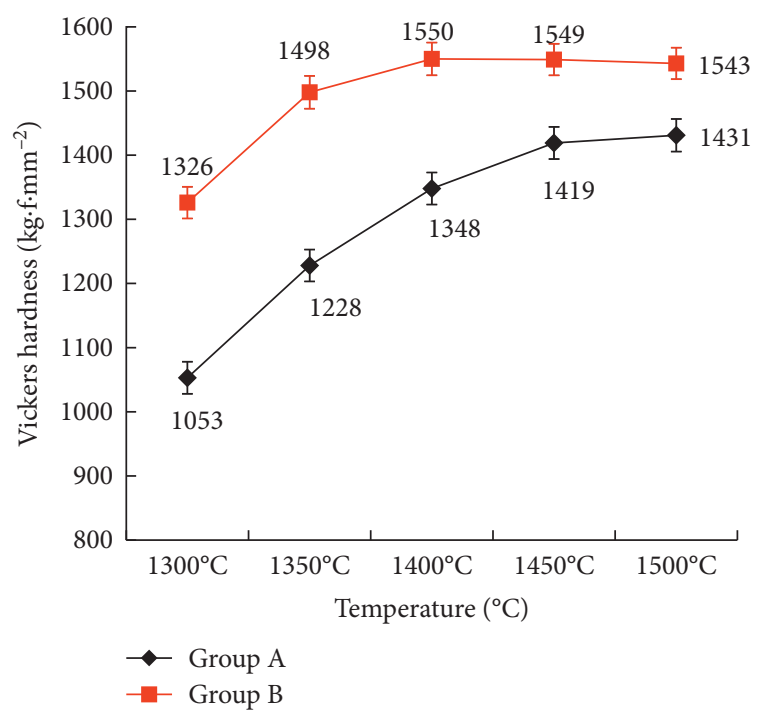

FIGURE 14: Vickers hardness of samples at different microwave sintering temperatures.

2 . Here, it is noted that similar and even higher fracture toughness values have been reported in microwave-sintered zirconia samples, for example, $9.52 \mathrm{MPa} \cdot \mathrm{m}^{1 / 2}$ for $3 \mathrm{Y}$-TZP [25], 11.22 MPa $\cdot \mathrm{m}^{1 / 2}$ for Ce-Y-TZP [26], and $11.62 \mathrm{MPa} \cdot \mathrm{m}^{1 /}$ 2 for $\mathrm{Al}_{2} \mathrm{O}_{3}(\mathrm{n}) / \mathrm{ZrO}_{2}$ [25].

By comparing the relative density, Vickers hardness, and fracture toughness data of two sets of samples in groups A and $\mathrm{B}$, the ceramic rings treated by microwave presintering perform better in all of these features and have a $100^{\circ} \mathrm{C}$ lower final sintering temperature than samples treated by conventional presintering. The microwave-sintered samples have smaller grain size and more uniform size distribution and thus have better performance. Here, it is noted that similar results have been reported in $\mathrm{TiC}[14], \mathrm{Li}_{2} \mathrm{TiO}_{3}$

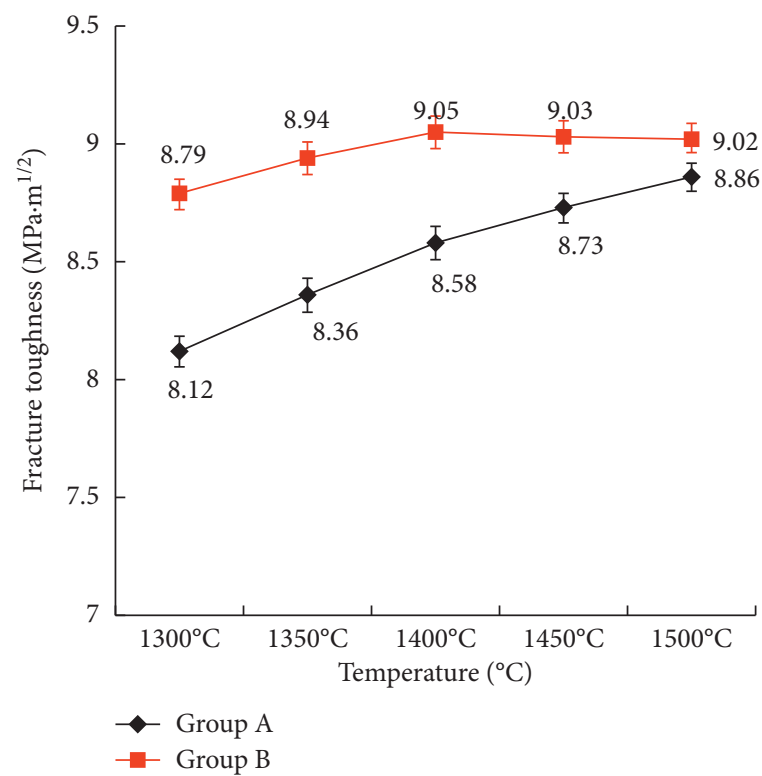

FIgURE 15: Fracture toughness of samples at different microwave sintering temperatures.

ceramic [27], $\mathrm{Li}_{2} \mathrm{TiO}_{3}-\mathrm{Li}_{4} \mathrm{SiO}_{4}$ biphasic ceramic pebbles [28], and other metallic and ceramic materials $[23,24]$.

\section{Conclusions}

In this paper, under the guidance of the simulation results, the cured 3Y-TZP ceramic rings are microwave-presintered to ensure the superior quality of the final samples. The best sample performance is achieved at a sintering temperature of $1400^{\circ} \mathrm{C}$, with an average particle size of $0.180 \mu \mathrm{m}$ and about $80 \%$ grain sizes distributed in the range of $0.1-0.2 \mu \mathrm{m}$; the relative density is about $99 \%$, and the Vickers hardness and fracture toughness reach $1550 \mathrm{~kg} \cdot f \cdot \mathrm{mm}^{-2}$ and $9.05 \mathrm{MPa} \cdot \mathrm{m}^{1 / 2}$, respectively. The samples that were sintered under the conventional presintering procedure and went through final microwave sintering at the temperature of $1500^{\circ} \mathrm{C}$ have an average particle size of $0.240 \mu \mathrm{m}$, about $70 \%$ of the grain sizes distributed in the range of 0.2 $0.3 \mu \mathrm{m}$, and the relative density of about $98 \%$, and the Vickers hardness and toughness fracture reached $1431 \mathrm{~kg} \cdot f \cdot \mathrm{mm}^{-2}$ and $8.86 \mathrm{MPa} \cdot \mathrm{m}^{1 / 2}$, respectively.

As a conclusion, the presintering process has an essential impact on the microstructure and overall performance of the final sintered sample; simulation-guided microwave presintering allows samples to obtain better properties with a $100^{\circ} \mathrm{C}$ lower final sintering temperature than conventional presintering. Microwave-sintered ceramic rings have improved mechanical performance, which are promising to be a substitution in the actual production.

\section{Data Availability}

The data that support the findings of this study are available from the corresponding author upon reasonable request. 


\section{Conflicts of Interest}

The authors declare no conflicts of interest.

\section{Acknowledgments}

This work was supported by the National Natural Science Foundation of China (51272111, 51673103, and 51973100) and the National Key Research and Development Project (2019YFC0121402).

\section{References}

[1] Y. Kong, J. Zhou, and Q. Chen, "Study on double refinement of carbide in GCr15 steel rings," Hot Working Technology, vol. 47, no. 2, pp. 224-227, 2018, in Chinese.

[2] J. Sun and B. Hao, "Study on the spinning performance of ceramic ring," China Fiber Inspection, vol. 19, pp. 85-87, 2014, in Chinese.

[3] M. Xue, S. Liu, X. Wang, and K. Jiang, "High fracture toughness of 3Y-TZP ceramic over a wide sintering range," Materials Chemistry and Physics, vol. 244, p. 122693, 2020.

[4] S. Ramesh, N. Zulkifli, C. Y. Tan et al., "Comparison between microwave and conventional sintering on the properties and microstructural evolution of tetragonal zirconia," Ceramics International, vol. 44, no. 8, pp. 8922-8927, 2018.

[5] G. Soon, B. Pingguan-Murphy, K. W. Lai, and S. A. Akbar, "Review of zirconia-based bioceramic: surface modification and cellular response," Ceramics International, vol. 42, no. 11, pp. 12543-12555, 2016.

[6] R. Bao, J.-H. Yi, Y.-D. Peng, and H.-Z. Zhang, "Effects of microwave sintering temperature and soaking time on microstructure of WC-8Co," Transactions of Nonferrous Metals Society of China, vol. 23, no. 2, pp. 372-376, 2013.

[7] N.-B. Zhang, C.-G. Bai, M.-Y. Ma, and Z.-Y. Li, "Preparation of $\mathrm{BaAl}_{2} \mathrm{O}_{4}$ by microwave sintering," Transactions of Nonferrous Metals Society of China, vol. 20, no. 10, pp. 2020-2025, 2010.

[8] E. C. David and H. S. Willard, "Microwave processing of materials," Annual Review of Materials Research, vol. 26, pp. 299-331, 1996.

[9] O. Kelly, L. Yannick, M. Pascal et al., "Influence of microwave sintering on electrical properties of BCTZ lead free piezoelectric ceramics," Journal of the European Ceramic Society, vol. 40, pp. 1212-1216, 2020.

[10] T. Fan, C. Ji, G. Chen et al., "Enhanced the dielectric relaxation characteristics of $\mathrm{BaTiO}_{3}$ ceramic doped by $\mathrm{BiFeO}_{3}$ and synthesized by the microwave sintering method," Materials Chemistry and Physics, vol. 250, p. 123034, 2020.

[11] K. K. Surthi, K. K. Kar, and R. Janakarajan, "Enhanced microwave sintering characteristics, electrical and thermal properties of nano $\mathrm{Li}_{2} \mathrm{TiO}_{3}$ ceramic and its nanocomposite using $\mathrm{LiNi}_{0.5} \mathrm{Co}_{0.5} \mathrm{PO}_{4}$ as high-capacity cathode for Li-ion batteries," Journal of Physics and Chemistry of Solids, vol. 135, p. 109099, 2019.

[12] R. F. K. Gunnewiek, C. P. F. Perdomo, I. C. Cancellieri, A. L. F. Cardoso, and R. H. G. A. Kiminami, "Microwave sintering of a nanostructured low-level additive $\mathrm{ZnO}$-based varistor," Ceramics International, vol. 135, 2020, in press.

[13] L. Qiao, Z. Wang, T. Lu, and J. Yuan, "Effects of microwave sintering temperature and holding time on mechanical properties and microstructure of $\mathrm{Si}_{3} \mathrm{~N}_{4} / \mathrm{n}-\mathrm{SiC}$ ceramics," Materials, vol. 12, no. 23, p. 3837, 2019.
[14] V. Nivedhita, N. A. N. Nihaar, B. Pavithra, A. Ashwath, and S. B. Prabu, "Effect of Ni addition on the densification of TiC: a comparative study of conventional and microwave sintering," The International Journal of Refractory Metals and Hard Materials, vol. 87, 2020.

[15] M. Darabi, M. Rajabi, and N. Nasiri, "Microstructural, mechanical and thermal properties of microwave sintered Cu-MWCNT nanocomposites," Journal of Alloys and Compounds, vol. 822, p. 153675, 2020.

[16] R. Benavente, M. D. Salvador, A. Centeno, B. Alonso, A. Zurutuza, and A. Borrell, "Study of microwave heating effect in the behaviour of graphene as second phase in ceramic composites," Materials, vol. 13, no. 5, p. 1119, 2020.

[17] S. Mohsin, B. M. Shoaib, M. Adnan et al., "Percolation phenomena of dielectric permittivity of a microwave-sintered $\mathrm{BaTiO}_{3}-\mathrm{Ag}$ nanocomposite for high energy capacitor," Journal of Alloys and Compounds, vol. 822, 2020.

[18] M. Hou, J. Gao, L. Yang et al., "The role of pre-alloyed powder combined with pressure-less microwave sintering on performance of superhard materials," Journal of Alloys and Compounds, vol. 831, 2020.

[19] Z. Zhao, G. Zhang, S. Wang, X. Zhao, and C. Guan, "Preparation of ultrafine cemented carbides with uniform structure and high properties by microwave sintering," Materials Letters, vol. 260, 2020.

[20] B.-h. Duan, Z. Zhang, D.-z. Wang, and T. Zhou, "Microwave sintering of Mo nanopowder and its densification behavior," Transactions of Nonferrous Metals Society of China, vol. 29, no. 8, pp. 1705-1713, 2019.

[21] D. Singh, A. Rana, P. Sharma, P. M. Pandey, and D. Kalyanasundaram, "Microwave sintering of $\mathrm{Ti}_{6} \mathrm{Al}_{4} \mathrm{~V}$ : optimization of processing parameters for maximal tensile strength and minimal pore size," Metals, vol. 8, no. 12, p. 1086, 2018.

[22] D. Jiao, X. S. Xiao, and J. L. Zhao, "Study on the debinding process of superfine zirconium dioxide injection molding," China Chemical Trade, vol. 3, no. 10, pp. 51-52, 2011, in Chinese.

[23] M. Oghbaei and O. Mirzaee, "Microwave versus conventional sintering: a review of fundamentals, advantages and applications," Journal of Alloys and Compounds, vol. 494, no. 1-2, pp. 175-189, 2010.

[24] C. Singhal, Q. Murtaza, and Parvej, "Microwave sintering of advanced composites materials: a review," Materials Today: Proceedings, vol. 5, no. 11, pp. 24287-24298, 2018.

[25] Y. Ai, X. Xie, W. He, B. Liang, and Y. Fan, "Microstructure and properties of $\mathrm{Al}_{2} \mathrm{O}_{3}(\mathrm{n}) / \mathrm{ZrO}_{2}$ dental ceramics prepared by two-step microwave sintering," Materials \& Design (1980-2015), vol. 65, pp. 1021-1027, 2015.

[26] S. K. Zhao and C. H. Xu, "Effects of $\mathrm{CeO}_{2}$ on the Mechanical Property and Microstructure of 3Y-TZP Nanocomposite Ceramic Die Material," Key Engineering Materials, vol. 434435, pp. 42-44, 2010.

[27] M. Yang, H. Wang, R. Chen et al., "Comparison of the microwave and conventional sintering of $\mathrm{Li}_{2} \mathrm{TiO}_{3}$ ceramic pebbles," Ceramics International, vol. 44, pp. 19672-19677, 2018.

[28] Y. Zeng, R. Chen, M. Yang et al., "Fast fabrication of high quality of $\mathrm{Li}_{2} \mathrm{TiO}_{3}-\mathrm{Li}_{4} \mathrm{SiO}_{4}$ biphasic ceramic pebbles by microwave singtering: in comparison with conventional sintering," Ceramics International, vol. 45, pp. 19022-19026, 2019. 